Table 1:. Volume and thickness of the bone-cartilage unit, femoral head volume and osteophyte area in healthy subjects (HS), osteoarthritis (OA) and rheumatoid Arthritis (RA) patients.

\begin{tabular}{|c|c|c|c|c|c|c|c|}
\hline & $\begin{array}{l}\text { Healthy } \\
\text { subjects } \\
(n=12)\end{array}$ & $\begin{array}{l}\text { Osteoarthritis } \\
\quad(n=12)\end{array}$ & $\begin{array}{c}\text { Rheumatoid } \\
\text { Arthritis } \\
(n=6)\end{array}$ & ANOVA & $\begin{array}{c}\text { OA vs } \\
\text { RA }\end{array}$ & $\begin{array}{l}\text { HS vs } \\
\text { RA }\end{array}$ & $\begin{array}{c}\text { HS vs } \\
\text { OA }\end{array}$ \\
\hline & \multicolumn{3}{|c|}{ Mean $[95 \% \mathrm{Cl}]$} & \multicolumn{4}{|c|}{$P$ - value } \\
\hline Age (years) & $62[60 ; 65]$ & $62[59 ; 65]$ & $63[60 ; 65]$ & 0.984 & - & - & - \\
\hline Gender $(\mathrm{M}: \mathrm{F})$ & $6: 6$ & $6: 6$ & $3: 3$ & 1.000 & - & - & - \\
\hline Femoral head volume $\left(\mathrm{cm}^{3}\right)$ & $52.0[39.6 ; 64.3]$ & $43.6[37.3 ; 50.0]$ & $41.1[33.6 ; 48.7]$ & 0.233 & - & - & - \\
\hline Articular cartilage volume $\left(\mathrm{cm}^{3}\right)$ & $7.4[5.9 ; 8.9]$ & $5.1[4.0 ; 6.1]$ & $2.9[1.6 ; 4.3]$ & $<0.001$ & 0.012 & $<0.001$ & 0.021 \\
\hline Articular cartilage thickness & 1413 & 1134 & $721[403 ; 1040]$ & $<0.001$ & 0.029 & $<0.001$ & 0.086 \\
\hline$(\mu m)$ & {$[1244 ; 1582]$} & {$[931 ; 1338]$} & & & & & \\
\hline $\begin{array}{l}\text { Subchondral bone thickness } \\
(\mu \mathrm{m})\end{array}$ & $227[172 ; 282]$ & $406[285 ; 527]$ & $409[186 ; 632]$ & 0.021 & 1.000 & 0.099 & 0.034 \\
\hline $\begin{array}{l}\text { Calcified cartilage thickness } \\
(\mu \mathrm{m})\end{array}$ & $108[81.1 ; 143]$ & $119[94.1 ; 151]$ & $56.6[25.3 ; 127]$ & $0.016 \dagger$ & 0.017 & 0.046 & 1.000 \\
\hline Osteophyte area $\left(\mathrm{mm}^{2}\right)$ & $8.8[2.2 ; 35.7]$ & $70.9[41.4 ; 121]$ & $49.2[4.7 ; 513]$ & 0.008 & 1.000 & 0.073 & 0.006 \\
\hline
\end{tabular}
distributed was log-transformed and presented as geometric mean $[95 \% \mathrm{Cl}]$.

Conclusion: Patients with secondary osteoarthritis due to rheumatoid arthritis had thinner articular cartilage and calcified cartilage but were otherwise not significantly different from patients with primary osteoarthritis. Thus, the inflammatory joint in rheumatoid arthritis was associated with a more pronounced loss of cartilage than the degenerative joint disease in primary osteoarthritis. The thicker calcified cartilage in primary osteoarthritis has been attributed to endochondral ossification; this does not seem to be the case in rheumatoid arthritis.

Acknowledgement: The authors are grateful for the technical assistance of Jette Barlach and Rita Ullerup. This work was financially supported by the Danish Rheumatism Association.

Disclosure of Interests: Rasmus Klose-Jensen: None declared, Anne Friesgaard Christensen: None declared, Louise Brøndt Hartlev: None declared, Lene Warner Thorup Boel: None declared, Mogens Berg Laursen: None declared, Kresten Krarup Keller Speakers bureau: Have received speaking fee from Pfizer, Ellen Margrethe Hauge Grant/research support from: Have received grants from Roche and Novartis, outside the submitted work., Speakers bureau: Have received personal fees from MSD, Pfizer, UCB and Sobi

DOI: 10.1136/annrheumdis-2019-eular.1409

\section{AB0797 GRANULYSIN MEDIATED CYTOTOXICITY AND ITS SERUM CONCENTRATION IN PATIENTS WITH KNEE OSTEOARTHRITIS}

1,2Gordana Laskarin *, Tatjana Kehler ${ }^{2,3}$, Viktor Persic ${ }^{4,5}$, Merica Aralica ${ }^{3}$, Božena Ćurko-Cofek ${ }^{6}$, Marija Rogoznica ${ }^{7}$, Ivan Rosovic ${ }^{4}$, Tamara KauzlaricZivkovic ${ }^{4}$, Sandra Rusac-Kukic ${ }^{4}$, Daniel Rukavina ${ }^{6,8} .{ }^{1}$ Faculty of Medicine, Department of Physiology and Immunology, Rijeka, Croatia; ${ }^{2}$ Specialized Hospital "Thalassotherapia-Opatija", Department of Rheumatology, Opatija, Croatia; ${ }^{3}$ Faculty of Health Studies, Department of Medical Rehabilitation, Rijeka, Croatia; ${ }^{4}$ Specialized Hospital "Thalassotherapia-Opatija", Opatija, Croatia; ${ }^{5}$ Faculty of Health Studies, Rijeka, Croatia; ${ }^{1}$ Faculty of Medicine, Department of Physiology and Immunology, Rijeka, Croatia; ${ }^{7}$ Specialized Hospital "ThalassotherapiaOpatija", Department of Rheumatology, Opatija, Croatia; ${ }^{8}$ University of Rijeka, Department of Biotechnology, Dept. Biomedical Sciences in Rijeka, Rijeka, Croatia

Background: In OA joint, synovial membrane contain immunocompetent cells (1-4), which produce predominantly pro-inflammatory cytokines $(2,5)$, justifying the name "osteoarthritis" and directing the development of disease towords mild systemic inflammatory condition (6). Granulysin (GNLY) is mediator of cellular immunity expressed in $\mathrm{T}$ and NK cells in $15 \mathrm{kDa}$ precursor and $9 \mathrm{kDa}$ cytotoxic forms (2). It is regulated by interleukin 15 . We investigated GNLY expression in perifperal blood lymphocytes and GNLY mediated apoptosis in vitro, serum concentration of $\mathrm{IL}-15$ and the correlation of GNLY expression with intensity of the pain in the knee of $\mathrm{OA}$ patients and with 6-minute walk distance.

Objectives: Women with knee OA (20), and healthy control (17) were medically examined, and their blood samples tested. All of them signed informed consent before medical sampling of peripheral blood (PB).

Methods: Visual analogue scale (VAS) of pain and results of 6-minute walk test were noticed in all participants. Peripheral blood mononuclear cells were isolated by gradient density centrifugation and intracellular GNLY labeling in CD3-CD56+NK cells, CD3+CD56- T cells and CD3 +CD56+ NKT cells was performed and analyzed by flow cytometry. NK cells' apoptotic activity against NK sensitive K-562 cells was measured in 18-hour PKH-26 (red) cytotoxicity assay with evaluation of propidium iodide-/annexin $V_{+}$target cells by flow cytometry. In some samples antiGNLY and/or anti-perforin antibodies were added. IL-15concentration was measured by ELISA. Nonparametric Kruskal-Wallis and Mann-Whitney Utest, as well as Spearman correlation test were used for statistical evaluation.

Results: In lymphocytes of OA patients GNLY expression and NK cellmediated apoptosis of K-562 cells did not differ significantly from the healthy control. In OA patients only, RC8 antibody against cytotoxic GNLY molecule significantly decreased apoptosis of K-562 cells. RF10 anti-15 kDa GNLY did not show such effect. Anti-perforin antibody completely abolished apoptosis in both groups tested and the effects of additionally added RC8 or RF10 anti-GNLY antibodies were not observed Serum IL-15 concentration in healthy controls and OA patients was low and did not show statistically significant difference. GNLY expression in lymphocytes, and particularly in NK subset, positively correlated with VAS of pain and 6-minutes walking distance.

Conclusion: In OA patients, GNLY mediated apoptosis is involved in apoptosis of NK sensitive K-562 cells in vitro and might be involved in the killing of damaged joint cells in vivo after direct contact.

\section{REFERENCES}

[1] Lindblad S, Hedfors E. Arthritis Rheum. 1987:30(10):1081-8.

[2] Wojdasiewicz P, et al. Mediators Inflamm. 2014;561459.

[3] Leheita O, et al. Egypt J Immunol 2005;12:113-24.

[4] Huss RS, et al.. Arthritis Rheum. 2010;62:3799-805.

[5] Imamura M, et al. Int J Inflam. 2015;2015:329792.

[6] Maldonado M, Nam J. Biomed Res Int. 2013;2013:284873.

Acknowledgement: The research was financed by the University of Rijeka Science Support No. Uniri-biomed-18-110 -1248 to Gordana Laskarin and by hospital ,,Thalassotherapia-Opatija“.

Disclosure of Interests: Gordana Laskarin Speakers bureau: Yes, at the professional meetings, Tatjana Kehler Speakers bureau: At some con gresses and meetings, Viktor Persic Speakers bureau: At some meetings and congresses, Merica Aralica: None declared, Božena Ćurko-Cofek: None declared, Marija Rogoznica: None declared, Ivan Rosovic: None declared, Tamara Kauzlaric-Zivkovic: None declared, Sandra Rusac-Kukic: None declared, Daniel Rukavina: None declared DOI: 10.1136/annrheumdis-2019-eular.6079

\section{AB0798 GENDER DIFFERENCES IN DURATION OF SYMPTOMS AND PREOPERATIVE EXPECTATIONS IN TOTAL KNEE ARTHROPLASTY PATIENTS}

${ }^{1}$ Daisy Latijnhouwers ${ }^{*}$, Claudia Leichtenberg ${ }^{1}$, Rob Nelissen ${ }^{1}$, Willem Jan Marijnissen ${ }^{2}$, Pieter-Jan Damen ${ }^{3}$, Thea Vliet Vlieland ${ }^{4}$, Maaike Gademan ${ }^{5}$, In addition to authors, the study group consist of: $\mathrm{H}$. van der Linden-van der Zwaag, B. Kaptein, LUMC; S. Vehmeijer, Reinier de Graaf Hospital, R. Onstenk, Groene Hart Hospital, S. Verdegaal, Alrijne Hospital, H. Kaptijn, LangeLand Hospital. ${ }^{1}$ LUMC, Orthopaedics, Leiden, Netherlands; ${ }^{2}$ Albert Schweitzer Hospital, Orthopaedics, Dordrecht, Netherlands; ${ }^{3}$ Waterland Hospital, Orthopaedics, Purmerend, Netherlands; ${ }^{4}$ LUMC, Orthopaedics, Rehabilitation and Physiotherapy, Leiden, Netherlands; ${ }^{5}$ LUMC, Orthopaedics and Clinical Epidemiology, Leiden, Netherlands

Background: The literature suggests that women with knee osteoarthritis (OA) perceive greater disability and a lower functional level before total 
knee arthroplasty (TKA) and undergo surgery at a later stage of the dis ease than men, which could lead to worse postoperative outcomes (1) These differences have been attributed to differences in the interpretation of symptoms between men and women (2), yet little is known about expectations of the postoperative outcomes of TKA

Objectives: To compare the duration of symptoms before TKA and the preoperative expectations of postoperative outcomes of TKA between men and woman.

Methods: Preoperative data from a multicenter cohort study on outcomes of primary TKA were used. Preoperatively, patients were asked to indicate the duration of symptoms to TKA ( $<1$ year, 1-5 years, 5-10 years and $>10$ years). The Hospital for Special Surgery (HSS) Knee Replacement Expectations Survey was used to obtain information on expectations regarding postoperative pain relief, mobility and daily activities and improvement of quality of life (score range 0-100), with lower scores indicating higher expectations. In addition, the Knee injury and Osteoarthritis Outcome Score (KOOS), pain (Numeric Rating Scale, NRS), comorbidities and work-status were gathered. Differences between men and women regarding the duration of symptoms and preoperative expectations were examined by the means of the Chi-Square test and independent t-test and difference with the $95 \%$ Confidence Interval $(\mathrm{Cl})$ respectively.

Results: A total of 1543 patients, 556 men (mean age 71 (SD 8), 32.3\% paid employment) and 987 women (mean age 71 (SD 9), 20.3\% paid employment) were included. Women had more pain preoperatively than men, 5.3 (SD 3) versus 4.3 (SD 3) at rest and 7.1 (SD 2) versus 6.2 (SD 3) during activity, respectively. Furthermore, men scored better on each KOOS subscale compared to women. Overall the duration of symptoms was longer in men than women: $<1$ year: $11.3 \%$ versus $9.6 \%, 1-5$ years: $38.8 \%$ versus $49.7 \%, 5-10$ years: $18.3 \%$ versus $20.0 \%$ and $>10$ years: $31.5 \%$ versus $20.7 \%$. Finally, women had significantly higher expectations of postoperative TKA outcomes than men, 67.4 (SD 19) and 70.2 (SD 19), respectively (Mean Difference; $2.79,95 \% \mathrm{Cl} 0.84-4.75$ ). Conclusion: Preoperatively, men reported a longer duration of symptoms and had lower expectations of TKA outcomes than women. However, men seemed to perceive less symptoms and restrictions in daily activities despite a longer duration of symptoms.

\section{REFERENCES}

[1] Katz JN, Wright EA, Guadagnoli E, Liang MH, Karlson EW, Cleary PD. Differences between men and women undergoing major orthopedic surgery for degenerative arthritis. Arthritis \& Rheumatism: Official Journal of the American College of Rheumatology. 1994;37(5):687-94.

[2] Parsley BS, Bertolusso R, Harrington M, Brekke A, Noble PC. Influence of gender on age of treatment with TKA and functional outcome. Clinical Orthopaedics and Related Research ${ }^{\circledR}$. 2010;468(7):1759-64.

Disclosure of Interests: None declared

DOI: 10.1136/annrheumdis-2019-eular.4120

\section{AB0799 ART- QUALIVIE: ASSESSMENT OF THE QUALITY OF LIFE OF PATIENTS WITH KNEE OSTEOARTHRITIS SIX MONTHS AFTER TREATMENT WITH THREE INTRA- ARTICULAR INJECTIONS OF ARTHRUM H 2\%}

${ }^{1}$ Milka Maravic ${ }^{*}$, Christian Pascaretti ${ }^{2}$, Paolo Insalaco ${ }^{2}$, Antoine Lesort ${ }^{3}$ Patrice Vincent ${ }^{4}$, Hakima Miotti ${ }^{5}$, Isabelle Bardoulat ${ }^{5}$, Cathy Maillard ${ }^{5}$. ${ }^{1}$ IQVIA Lariboisière (Hospital), Real World Insights/Rheumatology, La Défense/Paris, France; ${ }^{2}$ Le Ronceray Rheumatology, Angers, France; ${ }^{3}$ Hôpital Privé des Peupliers, Paris, France; ${ }^{4}$ LCA SA - LCA PHARMACEUTICAL, Chartres, France; ${ }^{5}$ IQVIA, La Défense, France

Background: Knee osteoarthritis (KOA) is a chronic condition affecting mainly the elderly and considered as the leading cause of disability after cardiovascular disease. KOA is characterized by functional discomfort and deformities, leading to a deterioration in the quality of life (QoL) of patients.

Objectives: The main objective was to demonstrate that 3 intra-articular injections of ARTHRUM H $2 \%$ improves the physical QoL of patients over a 6-month period.

Methods: A French observational, prospective, multi-centre study was conducted between 02/2016 and 07/2017 in patients over 40 suffering from Kellgren and Lawrence (KL) grade I, II or III primary KOA and treated with 3 intra-articular injections of ARTHRUM $\mathrm{H} 2 \%$. The variables included a questionnaire completed by a physician and the validated 12 items Short Form Health Survey (SF-12), completed by patients at baseline (right before the injections), and then at 90 and 180 days. The primary endpoint was the change in physical summary score from baseline to 180 days (paired Student t-tests). Logistic regression analyses were used to identify the mains drivers of significant increase of physical summary score, adjusted for sociodemographic and health covariates.

Results: Of the 134 patients treated with ARTHRUM $\mathrm{H} 2 \%$ included in the study, 115 were evaluable for the primary outcome (non-exploitable data for 19 patients).

The baseline characteristics of the analysable population were as follows: mean age of 66.4 years ( \pm 10.7$)$; majority female $(66.4 \%)$; mean BMI of $28.7( \pm 5.3) \mathrm{kg} / \mathrm{m}^{2}(43.3 \%$ overweight and $35.1 \%$ obese); $\mathrm{KL}$ grade $\mathrm{KOA}$ grade: I $13.6 \%$, II $40.2 \%$, III $46.2 \%$; localization: uni-compartmental $53.0 \%$ (78.6\% medial, $15.7 \%$ lateral, $5.7 \%$ patellofemoral), bi-compartmental $40.2 \%$ and tri-compartmental $6.8 \%$. Regarding management history respectively $6.7 \%$ and $44.8 \%$ of patients had previously received physical therapy or rehabilitation, and a visco-supplementation (2.2 treatments on average). Comorbidities observed in $73.9 \%$ of patients were metabolicrelated in $54.5 \%$, cardiovascular-related in $46.3 \%$, gastrointestinal-related in $20.9 \%$, and neurological-related in $8 \%$.

A clinically and statistically significant improvement in the QoL of patients was observed with an increase from 40.0 at baseline to 44.8 at 6 months $(p<0.001)$. A significant improvement was achieved during the 3 months following visco-supplementation (D0: 40.0 vs. D90: 44.8) and maintained from three to 6 months from baseline (D90: 44.8 vs. D180: 44.9)

The factors significantly associated with an improvement in QoL were: grade III KOA (OR=5.254, $\mathrm{p}=0.032)$, grade II KOA (OR=3.507, $p=0.100)$, lateral femorotibial osteoarthritis $(\mathrm{OR}=3.175, \mathrm{p}=0.029)$ and a single history of visco-supplementation ( $\mathrm{OR}=2.936, \mathrm{p}=0.044$ ).

Conclusion: ART-QUALIVIE is a French study providing real-world data on the evolution of QoL of visco-supplemented KOA patients. It has demonstrated the positive impact of ARTHRUM H $2 \%$ on the QoL of patients over the 3 months following injections maintained until 6 months after treatment.

\section{REFERENCES}

[1] Maheu E, Zaim M, Appelboom T, et al. Comparative efficacy and safety of two different molecular weight (MW) hyaluronans F60027 and Hylan G-F 20 in the symptomatic osteoarthritis of the knee (KOA). Results of a noninferiority, prospective, randomised, controlled trial. Clin Exp Rheumatol $2011 ; 29: 527-535$.

[2] Gandek B, Ware JE, Aaronson NK, et al. Cross-validation of item selection and scoring for the SF-12 Health Survey in nine countries: Results from the IQOLA Project. International Quality of Life Assessment, J Clin Epidemiol 1998:51(11):1171-1178.

Disclosure of Interests: Milka Maravic Consultant for: Previous 2014 MSD, Roche, Schering-Plough, Pfizer, Lilly, Employee of: ASTRAZENECA (2014-2017), Christian Pascaretti Consultant for: LCA Pharma, Paolo Insalaco Consultant for: LCA Pharma, Antoine Lesort Consultant for: LCA Pharma, Patrice Vincent Shareholder of: LCA Pharma, Employee of: LCA Pharma, Hakima Miotti: None declared, Isabelle Bardoulat: None declared, Cathy Maillard Employee of: Prior 2008 : BMS, Roche Janssen DOI: 10.1136/annrheumdis-2019-eular.2937

\section{AB0800 ESTABLISHMENT OF TECHNICAL PERFORMANCE CRITERIA AND REFERENCE INTERVALS FOR OSTEOARTHRITIS-RELATED SOLUBLE BIOMARKERS: THE APPROACH CONSORTIUM}

Anne-Christine Bay-Jensen ${ }^{1}$, Yves Henrotin ${ }^{2}$, Sven Lindemann ${ }^{3}$, Christoph Ladel ${ }^{3}$, Anne-Christine Hick ${ }^{2}$, Morten Karsdal ${ }^{1}$, Jonathan Larkin ${ }^{4}$, André Struglics ${ }^{5}$ ${ }^{6}$ Ali Mobasheri". ${ }^{1}$ Nordic Bioscience, Biomarkers and Research, Rheumatology, Herlev, Denmark; ${ }^{2}$ Artialis SA, Luik, Belgium; ${ }^{3}$ Merck KGaA, Darmstadt, Germany; ${ }^{4}$ Glaxosmithkline, Collegeville, United States of America; ${ }^{5}$ Lund University, Faculty of Medicine, Dept of Clinical Sciences Lund, Orthopaedics, Lund, Sweden; ${ }^{6}$ State Research Institute Centre for Innovative Medicine, Department of Regenerative Medicine, Vilnius, Lithuania

Background: Disease modifying therapy of osteoarthritis (OA) represents an unmet clinical need, and appropriate outcome measures are required that can robustly identify patients with different $O A$ phenotypes who may benefit from specific and more targeted therapies. APPROACH is an exploratory, 5-centre, 2-year prospective follow-up European cohort study. It entails extensive clinical, imaging, biomechanical and biochemica parameters, in a cohort recruited using machine learning models based on retrospective patient data to display a high likelihood of radiographic joint space width loss, MRI changes and/or knee pain over the course of the study. Biochemical markers (biomarkers) can be used to understand 